\title{
Solanes Corella, Ángeles. Derechos y Culturas. Los retos de la diversidad en el espacio público y privado, Tirant lo Blanch, Valencia, 2018
}

\author{
Juana María Gil Ruiz \\ Departamento de Filosofía del Derecho y Política \\ Universidad de Granada
}

Fecha de recepción 12/12/2018 I De publicación: 24/12/2018

La gestión de la diversidad cultural se afirma como uno de los pilares esenciales sobre el que se ha de construir la convivencia. El profesor Javier de Lucas, en el prólogo del libro, señala que su título, en el que se relacionan derechos y culturas, pone de manifiesto que esa vinculación constituye la perspectiva adecuada para afrontar los retos que la multiculturalidad representa. El subtítulo precisa más aún el triple ejercicio de análisis que se aborda en este trabajo: "observar la realidad, analizarla y aprehender los retos que plantean las actuales barreras para la convivencia en perspectiva jurídicopolítica", con la finalidad de estudiar, entender y proponer respuestas a los desafíos de la diversidad en el espacio público y en el privado. La profesora Ángeles Solanes, "una de las voces más autorizadas en el estudio del Derecho comparado de extranjería”, como señala de Lucas, presenta una propuesta que se vertebra en tres bloques temáticos interrelacionados para analizar los diferentes conflictos vinculados a la diversidad cultural.

I. Desde un punto de vista conceptual y a modo introductorio, la autora adopta un sentido amplio al referirse a la diversidad cultural, tomando en consideración factores como el lingüístico, el étnico, el nacional, el religioso o el identitario. De ahí que, a su entender, la diversidad cultural vendría constituida por la pluralidad de factores que da lugar al desarrollo de grupos sociales diversos que pretenden proyectar sus diferencias en el espacio público y conservarlas en el privado. Subrayar, por otro lado, que la perspectiva de género tiene un carácter transversal en todos los conflictos que se abordan, dada la necesidad de incorporar dicho enfoque a las líneas de trabajo de los poderes públicos $\mathrm{y}$, en concreto en este caso, a las políticas de gestión de la diversidad.

La noción de conflicto, concebido como un reto, es fundamental también en este trabajo. En ese sentido puede entenderse, en el planteamiento de Ángeles Solanes, cómo las desavenencias que se dan al intentar encontrar formas de conciliar, en palabras de Parekh, las reivindicaciones legítimas de 
unidad y diversidad, para lograr unidad política sin uniformidad cultural, sean inclusivas sin ser asimilacionistas y cultivar un sentido de pertenencia respetando las legítimas diferencias culturales.

A partir de esta premisa conceptual se procede a revisar las nociones de libertad e igualdad en las sociedades multiculturales, seleccionándose, a continuación, los aspectos claves para la gestión de los conflictos que plantea la diversidad cultural en la dimensión pública y privada. En este análisis se atiende particularmente a la realidad española, desde la regulación normativa hasta la jurisprudencia del Tribunal Supremo y el Tribunal Constitucional. En el marco del derecho comparado se estudian las resoluciones del Tribunal Europeo de Derechos Humanos y, puntualmente, del Tribunal de Justicia de la Unión Europea. Finalmente, se presentan una serie de propuestas que, más que conclusiones, son ideas para establecer políticas proactivas de la diversidad desde la neutralidad del Estado. La finalidad última no es otra que la de ofrecer alternativas trasladables a las políticas públicas para conseguir una sociedad que apueste por el reconocimiento, la representación y la redistribución en aras de una convivencia que suponga más que la coexistencia.

II. La necesidad de modular los marcadores primarios de identidad, (tales como la lengua, la religión, las tradiciones, los valores y las diferentes prácticas que se aúnan bajo la idea de cultura), conjugándolos con la dimensión garantista de los derechos humanos, es uno de los retos que deben abordar las políticas de gestión de la diversidad, tal y como señala y evidencia Ángeles Solanes al revisar la conexión entre derechos humanos, cultura e identidad, para a continuación analizar la integración desde la desigualdad material y la necesidad de construcción de un marco de referencia compartido.

Se impone en consecuencia una reflexión crítica acerca del alcance de la libertad y la igualdad entendidas como valores, principios, derechos y metaderechos. La libertad, negativa y positiva, expresa y realiza el valor moral de la autonomía personal, tomando en consideración el límite de la libertad ajena, pero, además, en su dimensión material exige del Estado los medios que permitan, tanto a los individuos como a los grupos culturales dotar de contenido otras libertades.

Fijado este contexto, la autora llama la atención sobre el hecho de que la coexistencia (que no convivencia) de diferentes culturas en un mismo ámbito espacial con valores y tradiciones diferentes es un desafío a enfrentar, desde la necesaria neutralidad estatal, sin renunciar a la libertad y a la igualdad. Una de las propuestas, de las diferentes que se estudian, y que permite la consecución de políticas públicas que favorezcan las denominadas $3 \mathrm{R}$ es la articulación del modelo de igual valoración jurídica de las diferencias. Este se basa en el principio normativo de la igualdad de los derechos fundamentales, 
con las debidas garantías para asegurar su efectividad, y los límites imprescindibles de la conjunción de estos.

Este enfoque exige posicionarse, por tanto, sobre la noción de cultura, la cual, para la autora hace referencia a un sistema de creencias, valores, costumbres y conductas, que los miembros de una sociedad utilizan, que son transmitidos entre generaciones a través del aprendizaje y que tiene un carácter histórico, complejo y dinámico. La interacción entre diferentes culturas es uno de los aspectos fundamentales en la trasformación cultural, aunque no sea fluida ni pacífica. Precisamente en este contexto es donde hay que ubicar la convivencia desde la libertad y la igualdad. Cuando determinados grupos se sienten amenazados en su especificidad se activa esa idea de pertenencia a la que la identidad cultural hace referencia. La identidad hace visible una cierta compacidad interna, unos rasgos que la definen hacia el exterior y un cierto carácter de separación y distinción hacía el exterior, una diferencia. La construcción identitaria manifiesta también la estratificación social y la imposibilidad para determinadas personas de reivindicar una identidad distinta de la clasificación que le es impuesta.

Este pormenorizado análisis que realiza Ángeles Solanes le permite remarcar que es fundamental evitar dos confusiones. El primer error puede ser el de no distinguir entre los casos en que las reivindicaciones para proteger la identidad cultural afectan a bienes y valores que, en último lugar, pueden considerarse sacrificables atendiendo a las normas del sistema legal del Estado, de aquellos otros supuestos en que el reconocimiento de dichas diferencias culturales puede resultar realmente problemático o incompatible con la protección de los derechos fundamentales y humanos, y por tanto con las exigencias del Estado democrático de Derecho. Una segunda incorrección consistiría en no delimitar el papel que efectivamente juegan las diferencias culturales para determinar o agravar cualquier conflicto social. Es imprescindible, desde este punto de vista, acotar si en determinados conflictos y tensiones la diversidad cultural es especialmente significativa o si, por el contrario, se apela a ella de forma equívoca porque lo que hay es una desigualdad manifiesta producto de una injusta redistribución.

No es irrelevante el hecho de que se tome en consideración los aspectos culturales en la dimensión jurídica, por ejemplo, en el caso de que los antecedentes culturales se incluyeran dentro de los aspectos subjetivos que permitieran al juez considerar los hechos para entender completamente el significado de la conducta del acusado y hacer posible la eventual imposición de la sanción sin que esta supusiera un trato desigual. Surgen aquí, como muestra este estudio, los peligros que la defensa cultural puede conllevar, frente a la cual, desde las reglas del Estado democrático de Derecho, hay que insistir 
en que la interpretación y la aplicación de las normas deben obedecer a criterios preventivos, con independencia de sus destinatarios, atendiendo al bien común y al interés superior.

La desconfianza entre diferentes grupos que se caracterizan por identidades fuertemente marcadas, potencia la asociación entre una determinada identidad cultural y comportamientos socialmente peligrosos vistos como amenazas. Precisamente la insistencia en presentar la diferencia como amenaza y conflicto, ante un ordenamiento jurídico que, en ocasiones, introduce medidas que pueden generar situaciones de desigualdad, potencia los actuales discursos que frente a la presencia de grupos culturalmente diversos los asocian a la extranjería y apuestan por pasar de la integración cívica promovida en las últimas décadas al giro antiinmigrante.

La apuesta por el modelo pluralista desde el reconocimiento de la diferencia puede permitir gestionar la convivencia multicultural para convertirla en intercultural, esto es, el paso de la mera coexistencia a la mutua interacción. El planteamiento de este estudio incide en la necesidad de construir un marco de referencia compartido desde la neutralidad cultural del Estado, superando la negación de la diferencia y estableciendo los requisitos mínimos de la vida en sociedad que permitan la convivencia pacífica.

En los distintos retos que se analizan en este trabajo la relación entre la cultura, la identidad y la autonomía individual adquiere especial importancia cuando se conjuga con el ejercicio de la libertad y la igualdad, y en concreto con el respeto de derechos como la libertad de pensamiento, conciencia y religión, por eso es ineludible gestionar la diversidad otorgándole un lugar compatible con el respeto y la garantía de los derechos humanos.

Para ello, y con la finalidad de proponer la implementación de políticas públicas proactivas ante la diversidad y planificar medidas de intervención, es necesario conocer cuáles son los principales conflictos en España y cómo han sido abordados a nivel supranacional desde el punto de vista jurisprudencial. Así se analizan las tensiones que aparecer en la dimensión pública, entendiendo por tal aquella que hace referencia al uso del espacio público, en el contexto de las sociedades multiculturales, entre ellos algunos seleccionados por haber suscitado importantes desacuerdos tales como la utilización de símbolos de pertenencia y el uso del espacio público, los límites de las prácticas alimentarias religiosas y por convicción, y la ubicación de los lugares de culto y los cementerios.

III. Por lo que se refiere a los símbolos de pertenencia Ángeles Solanes pone de relieve que el caso de la vestimenta religiosa es el que más conflictos ha generado, en concreto a propósito de la disputa sobre el velo islámico integral pero también en el no integral. En España el intento de 
establecer una normativa prohibitiva del velo integral fue frenado por la jurisprudencia. El Tribunal Supremo, en su sentencia de 14 de febrero de 2013, resolvió el recurso de casación contra el acuerdo del Pleno del Ayuntamiento de Lleida de 8 de octubre de 2010. El Tribunal estimó el recurso por entender que la modificación normativa excedía los límites de las competencias municipales y lesionaba la libertad religiosa de las recurrentes. En la misma línea se pronunció el Tribunal Superior de Justicia de Cataluña, en el auto de 29 de enero de 2015, al suspender la ejecutividad de la Ordenanza de Civismo de Reus.

En este trabajo se analiza la paradigmática sentencia del Tribunal Europeo de Derechos Humanos de 1 de julio de 2014, en el caso S.A.S. contra Francia, a propósito de la ley francesa que prohíbe la ocultación del rostro en el espacio público. En ella, el Tribunal avala esta prohibición a partir de la noción de convivencia, entendida como la interacción de los individuos en el espacio público, en la cual el rostro juega un papel fundamental. Deja así un amplio margen de discrecionalidad al Estado. El Tribunal descarta el ataque al principio de igualdad y no discriminación y la necesidad de proteger la seguridad. Se hace así hace prevalecer, de modo muy cuestionable como destaca Ángeles Solanes, la noción de convivencia, no reconocida en el Convenio Europeo de Derechos Humanos, frente al artículo 9 del mismo que protege la libertad religiosa. Además, es dudoso si la medida sancionadora es óptima, proporcional y necesaria para la consecución del fin perseguido. Esta jurisprudencia ha sido ratificada, a propósito de la ley belga de 1 de junio de 2011 y las disposiciones reglamentarias municipales de 2008, en los casos Belcacemi y Oussar contra Bélgica, y Dakir contra Bélgica ambos de 11 de julio de 2017.

Respecto a los velos no integrales, se recuerda que en la jurisprudencia del Tribunal Europeo de Derechos Humanos existe una larga tradición de prohibición, especialmente en el ámbito educativo, tal y como se puede inferir de la interpretación realizada en asuntos como Lucia Dahlab contra Suiza, Leyla Sahin contra Turquía, Kervanci contra Francia y Dogru contra Francia. En general, España es uno de los ejemplos de no prohibición del uso de vestimenta religiosa en los colegios, salvo casos puntuales como el del centro Camilo José Cela, recogido en la Sentencia del Tribunal Superior de Justicia de Madrid de 8 de febrero de 2013.

Por su parte, en el ámbito laboral, el Juzgado de lo Social n ${ }^{\circ} 1$ de Palma, en sentencia de 6 de febrero de 2017, ante prohibición similar consideró que se había vulnerado el derecho a la libertad religiosa de la trabajadora que prestaba sus servicios en la empresa Acciona Airport Services S.A.U. Esta resolución es coherente con los pronunciamientos de Tribunal de Justicia de la Unión Europea. 
Así, a partir de las sentencias de14 de marzo de 2017 en el asunto Samira Achbita y otros contra G4S Secure Solutions NV.; y el asunto Asma Bougnaoui y la Asociación de Defensa de los Derechos Humanos contra Micropole SA, dicho Tribunal apela a la legitimidad de una política de neutralidad en la empresa.

En otros supuestos como Barik Edidi contra España, de 26 de abril de 2016, el Tribunal Europeo de Derechos Humanos declara inadmisible la demanda de una letrada que fue expulsada de un juicio por llevar el hiyab, al entender que el comportamiento de la demandante había impedido que las jurisdicciones internas se pronunciaran sobre el fondo del asunto. Dentro del régimen penitenciario, la Sala de lo Penal de la Audiencia Nacional, en un auto de 17 de julio de 2017, ha prohibido el uso del velo islámico (hiyab) en las cárceles españolas si dificulta la identificación de las internas.

En cambio, en lo que atañe a los símbolos religiosos estáticos en el espacio público, la autora evidencia cómo la jurisprudencia española ha sido más unánime al considerar dichos símbolos como culturales, sin entender que conculcan el principio de aconfesionalidad. En ese sentido se pronunció, por ejemplo, a propósito del Cristo de Monteagudo, el Tribunal Supremo, en sentencia de 4 de marzo de 2013 y el Tribunal Superior de Justicia de Madrid en sentencia de 30 de enero de 2015; y en relación a la Cruz de la Muela, el Tribunal Supremo, en sentencia de 2 de diciembre de 2014. En dicha jurisprudencia se mantiene una línea semejante a la de la Gran Sala del Tribunal Europeo de Derechos Humanos en el caso Lautsi contra Italia en la sentencia de 18 de marzo de 2011, asumiendo un concepto de laicidad de contenido mínimo o esencial que va unido a la democracia liberal y al amplio margen de apreciación de los Estados.

Tratándose también de símbolos religiosos estáticos, se menciona un tema cuyo análisis exhaustivo, como se reconoce expresamente, supera las posibilidades de esta obra pero que, es imprescindible: la Ley de Memoria Histórica. Dicha norma recoge, en sus artículos 15, 16 y en la Disposición Adicional Sexta, referencias a los símbolos franquistas que afectan a los símbolos religiosos cuando tienen la forma de cruces. En estos supuestos, también se ha avalado el hecho de que símbolos como la cruz puedan ser considerados como de carácter cultural pero que hayan perdido ese carácter de "exaltación" al que se refiere la mencionada norma y que, por tanto, no proceda la retirada de los mismos, así por ejemplo lo ha sostenido el Tribunal Superior de Justicia de Galicia en sentencia de 5 de febrero de 2015. En opinión de la autora, la precisión legal respecto a la finalidad de la realización del símbolo en cuestión es interesante y acertada en la medida en que permite desarticular visiones parciales. Así, es necesario atender tanto al propósito que los símbolos tuvieron en su 
momento de realización, como a la función que han desarrollado más tarde, para no soslayar la voluntad de memoria democrática que la ley consagra.

En el espacio público pueden suscitarse tensiones o problemas en la utilización de la vía pública a propósito de la realización de actividades culturales. Cuando se trata de grupos minoritarios, hay dos elementos fundamentales para que esas actividades se realicen en la vía pública: el deseo de visibilización pública y la voluntad de reconocimiento social. De la normativa genérica que se analiza se desprende que las actividades culturales y religiosas que se realicen en la vía pública han de tener la misma consideración que cualquier actividad privada que tenga una repercusión pública, sin embargo, se han suscitado problemas apelando al orden público. En opinión de la autora es imprescindible, desde la aplicación de la legalidad y en estrictas condiciones de igualdad, definir cómo formular, tramitar, afrontar y resolver, desde el punto de vista de la gestión administrativa, las demandas que tienen que ver con cuestiones como la utilización de la vía pública. Sin duda, la interlocución habitual con los grupos minoritarios con implantación en el municipio puede favorecer esa anticipación, sin olvidar que es necesario concretar los recursos para dar respuesta a estas demandas.

El segundo de los conflictos en el espacio público hace referencia a las prácticas alimentarias religiosas y por convicción en centros públicos como los colegios, los hospitales, los centros penitenciarios y de internamiento de extranjeros. Respecto a esta cuestión, no existe una obligación normativa al respecto, sino más bien una declaración de intenciones. Esa ausencia de una obligación de resultado ha hecho que las solicitudes planteadas por las diferentes confesiones religiosas no hayan sido atendidas argumentado diferentes razones. Entre ellas, el desproporcionado nivel de exigencia y diferenciación en el uso de los servicios públicos, que no sería acorde con la racionalidad y con la limitación que tienen los fondos públicos. Como se evidencia en este trabajo, este tipo de argumentos no son sostenibles.

Así lo ha considerado la jurisprudencia del Tribunal Europeo de Derechos Humanos, que entiende que no puede otorgarse mayor valor a argumentos de índole material que a la realización de los derechos de libertad religiosa, de conciencia y de pensamiento. En el caso Jakóbski contra Polonia, de 7 de diciembre de 2010, por ejemplo, dicho Tribunal consideró que las autoridades polacas atentaron contra la libertad religiosa del recurrente, vulnerando el artículo 9 Convenio, al impedirle seguir en prisión un régimen específico, sin carne ni pescado, como prescribía su religión. En este caso se apreció vulneración del artículo 14 del Convenio por trato discriminatorio.

El Tribunal en diferentes casos busca el equilibrio entre el derecho a una dieta determinada, 
como demanda razonable, y las limitaciones a las que tiene que hacer frente la administración en el caso de personas en situación de reclusión, por ejemplo, en el asunto Vartic contra Rumania, de 17 de diciembre de 2013. Ello no significa que no existan límites a estas peticiones. El Tribunal Europeo de Derechos Humanos (en el caso Hoffmann contra Austria, de 23 junio 1993; Manoussakis y otros contra Grecia, de 26 de septiembre de 1996 y Larissis contra Grecia, de 24 de febrero de 1998) y el Tribunal Constitucional (entre otras en sentencias de 27 de junio de 1990 y de 29 de junio de 1998), ya habían señalado que tal derecho está sometido a los límites del respeto a los derechos fundamentales ajenos y otros bienes jurídicos protegidos.

La jurisprudencia de los tribunales españoles ha actuado en sentido inverso a la europea. En el caso de los centros educativos, por ejemplo, el Tribunal Superior de Justicia de Madrid, en sentencia de 16 de junio de 2015, consideró que el servicio de comedor en las escuelas es voluntario. Por ello atendiendo a la racionalidad, la proporcionalidad y el respeto a terceros, no puede considerarse que la libertad religiosa deba llevarse al extremo de exigir que el servicio público articule una organización individualizada. En relación a los centros penitenciarios, se ha justificado la falta de un menú específico vegetariano por considerarlo innecesario.

Con la finalidad de revertir estas situaciones, que irán en aumento en España, la autora procede a puntualizar algunas cuestiones. La cuestión fundamental en estos casos es asegurar un mínimo coherente con una concepción de la igualdad entendida como igualdad de recursos, en el sentido que señala Dworkin. Aquello que exceda el mencionado principio podría entenderse como un coste de oportunidad que cada individuo debe concebir en relación con su capacidad de autodeterminación, que se traduce en aspiraciones y prioridades. Se trata de buscar así un equilibrio entre libertad y responsabilidad. En líneas generales, el mandato dirigido a las autoridades no contiene una obligación de resultado, pero la situación de sujeción no voluntaria, en los casos de privación de libertad y, además, de especial dificultad, en la que se encuentra los sujetos, deberían ser tomadas en consideración. Como se pone de manifiesto en las diferentes guías de buenas prácticas analizadas en el trabajo presentado, para que se incluyeran menús que respetaran los preceptos confesionales sería necesario tomarlos en consideración en los pliegos de cláusulas contractuales que negocia la administración.

Un tercer conflicto que reclama también la supervisión legal y jurisprudencial, es el relativo a la distribución del suelo en el espacio público compartido, en el que los diferentes grupos religiosos se visibilizan y han de normalizar su presencia. De la conjunción del artículo $16 \mathrm{CE}$, con otros preceptos 
constitucionales como los artículos 9.2, 13.1, 14 y 47, se concluye que la utilización del suelo, para la ubicación de lugares de culto y cementerios, tiene influencia sobre el efectivo ejercicio y garantía del derecho fundamental de libertad religiosa. Desde la perspectiva de la legislación urbanística, los centros religiosos tienen la consideración de equipamientos comunitarios.

En España se han suscitado diferentes problemas en torno a la ubicación de mezquitas, oratorios y otros lugares de culto. En particular, como se documenta en este estudio, el caso del barrio de Singuerlín en Santa Coloma de Gramenet, sobre la ubicación de un oratorio, que se solucionó habilitando unos barracones en un polígono industrial, que a día de hoy aún continúan. Algunos casos problemáticos han llegado a sede judicial generándose jurisprudencia a favor del derecho de establecimiento de lugares de culto de diferentes confesiones religiosas. Así, por ejemplo, el Tribunal Supremo en sentencia 4 de mayo de 2016, desestimó el recurso de casación interpuesto por el Ayuntamiento de Bilbao. Dicho Ayuntamiento, aprobó una modificación de su Plan General de Ordenación Urbana para establecer que el uso religioso sería incompatible con el uso residencial, y el Tribunal confirmó la anulación de esa modificación entendiendo que en su aprobación no se había permitido la preceptiva participación de las confesiones religiosas afectadas.

El Tribunal Europeo de Derecho Humanos no ha ofrecido una noción precisa de lo que se considera un lugar de culto, pero de su jurisprudencia se desprenden características que permiten identificarlo y protegerlo a través del artículo 9 del Convenio. Dicho Tribunal, ha considerado lugares de culto aquellos en los que se realiza la transmisión de dogmas de las diferentes confesiones, puede ser una mera habitación (como en el caso Manoussakis y otros c. Grecia 26 de septiembre de 1996) o un lugar compartido con otras confesiones (como en el asunto Kuznetsov y otros c. Rusia, de 11 de enero de 2007).

Ahora bien, no se considera lugar de culto si en este no se práctica de forma permanente y durante cierta duración, por ejemplo, en los casos de reuniones en domicilios (como se señala en la sentencia Boychev y otros c. Bulgaria, de 27 de enero de 2011), en la oración que se desarrolla en un local alquilado por una ONG (como en el asunto Masaev c. Moldavia, de 12 de mayo de 2009), o en un lugar público como un parque (como en el caso Barankevich c. Rusia de 26 de julio de 2007). El Tribunal concede incluso la protección del artículo 9 del Convenio a la ceremonia religiosa musulmana celebrada en los locales de un partido político en el que había símbolos de una organización terrorista (en el caso Güler y Ugur c. Turquía, de 2 de diciembre de 2014). En síntesis, el Tribunal Europeo de Derechos Humanos ha entendido que, aunque sea recomendable, no existe una obligación legal por 
parte de las autoridades de garantizar a cada comunidad religiosa un lugar de culto, puesto que, no estamos ante un servicio de responsabilidad pública.

Los múltiples inconvenientes a los que tienen que hacer frente algunas confesiones en la ubicación de sus lugares de culto, exige respuestas por parte de las instituciones públicas. Entre ellas, en este trabajo se apuesta por los denominados espacios multiconfesionales o centros pluriconfesionales. Estos equipamientos religiosos tendrían la ventaja de ser propiedad de la administración pública de tal forma que esta sería la encargada de su construcción, mantenimiento y conservación. De esta manera, se posibilitaría el ejercicio de la libertad religiosa en condiciones de igualdad por parte de creyentes de distintas confesiones, garantizándoles un lugar donde poder realizar los actos religiosos. La administración en este caso estaría obligada a reservar un espacio para dicho centro, que quedaría incluido dentro del estándar urbanístico de uso cívico-asociativo, como consecuencia de hacer efectivo el principio de cooperación. Las formas de articular dichos espacios son diversas: sería posible la elaboración, por ejemplo, de un Plan Municipal de Lugares de Reunión que debería incluir un apartado específico para los lugares de culto y las demandas de las diferentes confesiones; o bien, otra alternativa, pasaría por proponer una ley estatal que regulara las condiciones mínimas para el establecimiento de los lugares de culto en condiciones de igualdad material.

En el mismo sentido, para acomodar la diversidad religiosa, sería necesario abordar la ubicación de los cementerios municipales y los tanatorios. En el trabajo se acude a la jurisprudencia del Tribunal Europeo de Derechos Humanos acerca de la ubicación de los cementerios para ilustrar que, como se señalaba anteriormente, el artículo 9 del Convenio ha servido para proteger el derecho a crearlos y gestionarlos, tal como se constata, por ejemplo, en el asunto La Iglesia de Jesucristo de los Santos de los Últimos Días contra Reino Unido, de 4 de marzo de 2014.

En el caso español, de los conflictos analizados, se concluye la necesidad imprescindible de actualizar la legislación nacional y armonizar la de las diferentes Comunidades Autónomas para evitar desigualdades manifiestas. Las diferentes recomendaciones elaboradas por distintas instituciones públicas españolas, han apostado también en este caso, por la multiconfesionalidad respetando el ejercicio de la libertad religiosa en la diversidad, y tomando en consideración el carácter limitado del espacio.

IV. Junto a estos conflictos en este trabajo se procede a analizar aquellos otros que plantean importantes retos en el ámbito privado. Los problemas que se han elegido se ubican en el derecho de familia, en concreto en el contexto de la institución del matrimonio, porque como mantiene Ángeles 
Solanes, la familia es un espacio aglutinador del encuentro intercultural entre formas de vida familiar procedentes de círculos culturales, religiosos, sociales y jurídicos muy alejados.

El primero de los conflictos que se analiza en esta parte hace referencia al matrimonio islámico, especialmente a los requisitos que son necesarios para que se reconozca efectos civiles en el ordenamiento jurídico español. Según el artículo 7 de la Ley 26/1992, existen dos vías para el reconocimiento del matrimonio islámico. La regla general es que la celebración del matrimonio requiere, con carácter previo, la instrucción de un expediente, para que el instructor del mismo se cerciore de que ambos solicitantes pueden contraerlo, y expida así el certificado de capacidad matrimonial cuando se reúnan los requisitos señalados en el Código civil. Como norma especial se permite a los contrayentes celebrar el matrimonio sin la previa instrucción del expediente siendo, entonces, especialmente importante la inscripción registral, puesto que, será el momento en el que se pueda realizar el control de tales requisitos.

Es básico insistir en la reforma realizada en el Código Civil por la Ley 15/2015 de Jurisdicción Voluntaria. Con esta disposición, el artículo 7 de los tres Acuerdos suscritos con la FEREDE, FCIE y CIE, ha sido modificado para clarificar los trámites, si se quiere que las distintas formas de celebración del matrimonio tengan efectos civiles. Se intenta hacer frente a los múltiples problemas suscitados por la falta de expediente. Así, por ejemplo, la sentencia del Tribunal Constitucional de 1 de diciembre de 2014 ilustra un caso, no tan extraordinario, de concesión de efectos jurídicos a esta modalidad de matrimonio sin expediente previo. El Tribunal Europeo de Derechos Humanos en el asunto Muñoz Díaz contra España, de 8 de diciembre de 2009, ya había dejado claro que no se equipara el matrimonio no reconocido al no inscrito, ni tampoco a la convivencia more uxorio.

Con la reforma de 2015 expresamente se señala que el ministro de culto o el representante de la comunidad debe incluir el expediente previo ya tramitado, enviándolo en el plazo de cinco días al Encargado del Registro Civil. Con todo, una de las críticas que puede hacerse es que la Ley de la Jurisdicción Voluntaria no ha servido para uniformar el sistema matrimonial español, ya que, no cuestiona la celebración del matrimonio en sus diferentes formas religiosas.

Por otra parte, las instituciones islámicas vinculadas al matrimonio que mayores inconvenientes generan en España son la poligamia y el repudio. Ambas se dan, respectivamente, en el momento de la constitución y la disolución del vínculo matrimonial. Por lo que se refiere a la poligamia, existe un rechazo de la misma en el marco legal español por entender que choca directamente contra el orden público interno e internacional, por lesión de derechos fundamentales y de la moralidad pública, como 
elemento ético común de la vida social. La jurisprudencia del Tribunal Supremo, por ejemplo, en las sentencias de 19 de junio de 2008, 26 de febrero de 2010, 10 de octubre de 2011 y 19 de diciembre de 2011, entre otras, deniega la concesión de la nacionalidad española por poligamia, incidiendo en la falta de integración.

Respecto a la poligamia no pueden olvidarse las dos excepciones en cuanto a la pensión de viudedad que se derivan de los Acuerdos suscritos entre España, Marruecos y Túnez. Así, la consideración jurisprudencial que no admite que el matrimonio poligámico genere efectos jurídicos en el ámbito español, encuentra algunas salvedades en el orden social. Esta opción atiende al principio de justicia material que evita consecuentemente convertir en perjuicio lo que debiera actuar en protección de la mujer discriminada por poligamia.

No se trata, en todo caso, de una jurisprudencia unánime. El Tribunal Supremo, en Auto de 28 de marzo de 2017, declara la inadmisión del recurso de casación para la unificación de doctrina, contra la resolución de la Sala de lo Social del Tribunal Superior de Justicia de Cataluña, de 25 de abril de 2016. En este sentido, desestima la demanda de la actora en relación al reconocimiento de la pensión de viudedad vinculada al matrimonio poligámico que se realizó en Gambia. En cambio, el Tribunal Supremo en sentencia de 24 de enero de 2018 ha reconocido la situación de poligamia a los efectos del reparto de la pensión de viudedad a las esposas de un súbdito marroquí. El fallecido había percibido prestación de retiro atendiendo a la legislación de clases pasivas. La recurrente en casación era la segunda esposa, teniendo reconocida la primera de ellas la pensión de viudedad. El Tribunal Superior de Justicia denegó la posibilidad de beneficiarse de la pensión de viudedad a la segunda esposa alegando que la situación de poligamia está prohibida y penalizada en España, resulta incompatible con las normas aplicables y además pone de manifiesto la situación de desigualdad entre mujeres y hombres.

Asimismo, existen múltiples complicaciones para que la institución del repudio surta efectos civiles en España. Resulta relevante tomar en consideración que el artículo 954 de la Ley de Enjuiciamiento Civil, exige para el exequatur que la obligación para cuyo cumplimiento se haya procedido sea lícita en España. Ello no ocurre, en principio, en el caso del repudio, especialmente, en el repudio unilateral. Una estricta aplicación del orden público en este supuesto podría resultar lesiva para la tutela judicial efectiva de la mujer. Sin embargo, entiende la profesora Ángeles Solanes que tiene razón la parte de la doctrina que sostiene que la mujer repudiada, al solicitar la ejecución de la decisión de repudio legalizada en el ordenamiento de origen, está manifestando la ausencia de una voluntad 
matrimonial y la ratificación del repudio en aras a la consecución de un mejor derecho. El repudio, en todo caso, no podrá tener efectos jurídicos en España si, además de los requisitos que le son legalmente exigibles, no es irrevocable.

2. En el segundo de los conflictos en el ámbito privado, Ángeles Solanes continúa analizando la institución matrimonial, abordando el estudio del matrimonio de conveniencia, forzado e infantil, estos dos últimos desde una perspectiva penal. En el matrimonio de conveniencia, caracterizado por el abuso y fraude de ley que subyace, se incluyen aquellas uniones celebradas con la única finalidad de regularizar la situación en España de uno de los contrayentes, mediante el matrimonio con español o con quien ya se encuentra legalmente en el país. Las múltiples resoluciones de la Dirección General de los Registros y del Notariado que se analizan en este trabajo permiten concretar los indicios para calificar un matrimonio como de conveniencia. Entre ellos, por ejemplo, la imposibilidad de comunicación a través de una lengua común o el desconocimiento de las circunstancias personales y familiares de la pareja. Desde el punto de vista de la autora no es necesario insistir en un mayor control, más bien lo contrario. Asimismo, enfatiza la jurisprudencia más reciente del Tribunal Supremo, sentencia de 6 de abril de 2017, que en opinión de la autora opta acertadamente por la exclusión de respuesta penal en el caso de matrimonio de conveniencia. Es más, expresamente se señala que el interés del legislador por estos matrimonios no suele ser ni por la protección de los derechos humanos vinculados al matrimonio, ni por la protección de la institución matrimonial, sino por la vulneración de la normativa de extranjería, de tal manera que si ésta no existe, el consentimiento prestado no es cuestionado aunque puede suponer un ilícito civil.

El caso de los matrimonios forzados hace referencia a la unión de dos personas en la que al menos una de ellas no ha dado su libre y pleno consentimiento para contraer matrimonio. La característica fundamental de estos matrimonios es el uso de la violencia física y psíquica para doblegar la voluntad y obligar al menos a una de las partes a la unión. Los matrimonios forzados son una de las múltiples manifestaciones de la violencia hacia las mujeres que tiene su origen común en las desigualdades de género y, además, ahondan en el debate sobre su autonomía y las características del consentimiento libre. En instrumentos internacionales como los del CEDAW se insiste en que el matrimonio forzado es una práctica discriminatoria, cuya erradicación es imprescindible en la línea del Convenio del Consejo de Europa sobre la prevención y lucha contra la violencia contra las mujeres y la violencia doméstica, hecho en Estambul el 11 de mayo de 2011. Este estudio ahonda en la compleja delimitación entre matrimonios pactados y matrimonios forzados, dado que estos últimos pueden ser 
inicialmente matrimonios concertados en origen y viceversa. Tampoco puede pasarse por alto, en ocasiones, su conexión con otros delitos como la trata de seres humanos.

En el caso de España, en opinión de la autora, puede valorarse positivamente la reforma del Código Penal de 2015, en concreto del artículo 172 bis, que se ocupa de la tipificación de esta práctica. Con todo, una de las principales ausencias de este precepto es la relativa a la falta de una circunstancia cualificante que haga referencia a las relaciones entre el autor y la víctima. Podría acudirse a las circunstancias agravantes genéricas, como el abuso de la situación de superioridad, la de confianza, o la circunstancia mixta de parentesco. En tal caso, habría que especificar, cómo apreciar esta circunstancia en el delito de matrimonio forzado, si como una agravante, por el ataque al bien jurídico de la libertad, o como una atenuante, tomando en consideración el factor cultural. En opinión de la autora, habría que optar por la primera interpretación. Hasta ahora, el Tribunal Supremo, por ejemplo, en la sentencia de 11 de mayo de 2009, ha tomado en consideración la existencia de mutilación genital y matrimonio forzado para conceder la condición de refugiada y el derecho de asilo en España.

En estrecha conexión con este supuesto se aborda el caso de los matrimonios infantiles. Dicho matrimonio hace referencia a aquel en el que al menos uno de los contrayentes es un niño, entendiendo por tal al menor de 18 años, salvo que, en virtud de la ley que le sea aplicable, haya alcanzado antes la mayoría de edad. El Comité de los Derechos del Niño ha exhortado a los Estados partes a que revisen la mayoría de edad si esta se encuentra por debajo de los 18 años. El análisis de diferentes resoluciones de Naciones Unidas y del Consejo de Europa, pone en evidencia la necesidad de articular políticas y legislaciones para poner fin a estos matrimonios. Para ello es necesaria la colaboración de las comunidades que los practican.

En España el matrimonio infantil aparece regulado en el artículo $172.3 \mathrm{CP}$ como un tipo cualificado agravado del matrimonio forzado, sin embargo, esta precisión de la reforma de 2015 sería mejorable. A juicio de la profesora Ángeles Solanes, es acertada la crítica a la alusión genérica a las penas que permite bien prisión o bien solo multa, cuando a tenor de la conducta agravada sería más pertinente la pena más grave.

El último de los conflictos analizados se refiere a los denominados como crímenes de honor. En estos casos, como recuerda Ángeles Solanes, el concepto de honor tiene una dimensión colectiva o grupal, más que estrictamente individual, y va unido a lo que podrían considerarse culturalmente los códigos de honor. Desde Naciones Unidas se insiste en la necesidad de que la legislación incluya una definición amplia de crímenes de honor que abarque todos los actos de discriminación y violencia para 
preservar el honor de la familia. Las diferentes resoluciones y recomendaciones de la Asamblea General de Naciones Unidas, los instrumentos internacionales como la CEDAW y el Convenio de Estambul, establecen estándares específicos que marcan la actuación de los Estados miembros para la prevención, prohibición y erradicación de dichas prácticas.

El Tribunal Europeo de Derechos Humanos se ha ocupado de algunos supuestos relacionados con los crímenes de honor a propósito de asuntos vinculados a la violencia doméstica (como en el caso Opuz contra Turquía, de 9 de junio de 2009) y a las expulsiones (como en la sentencia $N$. contra Suecia, de 20 de julio de 2010). El criterio del Tribunal Europeo de Derechos Humanos ha sido más estricto a propósito de las expulsiones al entender que, por ejemplo, en relación a Estados como Yemen o Irak, no era necesaria la protección (como se señala, en el asunto A.A. y otros c. Suecia, de 28 de junio de 2012 y en los casos D.N.M. contra Suecia y S.A. contra Suecia, ambos de 27 de junio de 2013). En el derecho comunitario, la Directiva 2012/29/UE, por la que se establecen normas mínimas sobre los derechos, el apoyo y la protección de las víctimas de delitos, alude a los delitos relacionados con el honor, como manifestación de la violencia por motivos de género.

España no cuenta con una normativa concreta que se ocupe de los crímenes de honor, sino que esta práctica queda subsumida dentro de la violencia de género y se reconduce a diferentes tipos de delitos. Por ello se repasan en el trabajo las disposiciones básicas que se ocupan de dicha violencia, incluyendo el Real Decreto-ley 9/2018, de 3 de agosto, de medidas urgentes para el desarrollo del Pacto de Estado contra la violencia de género que ha introducido modificaciones en la LO 1/2004 en los artículos 20 a 23. Es especialmente reseñable la reforma del artículo 23, reiteradamente reclamada, que pretende concretar y ampliar los títulos judiciales habilitantes para acreditar la condición de víctima de violencia de género; $y$, por otra parte, establecer otros títulos no judiciales habilitantes para los casos en los que no hay denuncia y tampoco existe procedimiento judicial abierto.

La reforma del Código Penal de 2015 no ha incluido una mención expresa a los crímenes de honor. En esta modificación es reseñable la introducción de la agravante de género en el art. 22.4 CP. Por otra parte, la Ley de Jurisdicción Voluntaria, incluye dos cuestiones relacionadas con la violencia de género que influyen también en los casos de crímenes de honor. Por un lado, se impide contraer matrimonio a los condenados por haber participado en la muerte dolosa de la pareja de hecho. Por otro lado, se amplían las causas de indignidad sucesoria también a quienes hubieran sido condenados por otros delitos de violencia doméstica y de género.

Desde la perspectiva jurisprudencial, hasta el momento, los crímenes de honor han sido 
reconducidos a diversos tipos penales en función de las circunstancias concurrentes y sin atender al concepto de honor. El Tribunal Supremo, por ejemplo, en sentencia de 11 de julio de 2011, recoge una definición de honor en virtud de la cual este hace referencia a la dignidad personal reflejada en la consideración de los demás y en el sentimiento de la propia persona, cuyo contenido es cambiante. El Tribunal Constitucional por su parte, en sentencia 14 de diciembre de 2014, insiste en que el denominador común de todos los ataques ilegítimos al honor es el desmerecimiento en la consideración ajena. El honor, por tanto, conecta con los delitos del Título Décimo Primero (XI) del Código Penal.

Con los conflictos analizados se evidencia, en palabras de Ángeles Solanes, que en el espacio público concurre un objetivo central para las democracias pluralistas, que no es otro que evitar que la diversidad cultural se convierta en distinción social y surjan nuevas formas de desigualdad. Ese objetivo persiste en el ámbito privado, especialmente en la institución del matrimonio. Para poder afrontar y gestionar estas desavenencias, es imprescindible el reconocimiento, la redistribución y la representación, desde la neutralidad del Estado. Por eso, abordar la gestión de la diversidad cultural es, en el fondo, una cuestión de igualdad y de simetría en el poder social. Este libro invita a reflexionar críticamente, desde el análisis riguroso, sobre los diferentes retos señalados, ofreciendo alternativas trasladables a políticas públicas para la construcción de un marco común compartido desde los derechos humanos y la interculturalidad. 